Case Report

\title{
Successful Conservative Treatment of an Elderly Patient with Corrosive Proctocolitis
}

\author{
Chalerm Eurboonyanun $\mathbb{D}^{1}{ }^{1}$ Somchai Ruangwannasak, ${ }^{1}$ Kulyada Eurboonyanun, ${ }^{2}$ \\ and Anan Sripanuskul ${ }^{1}$ \\ ${ }^{1}$ Department of Surgery, Faculty of Medicine, Khon Kaen University, Thailand \\ ${ }^{2}$ Department of Radiology, Faculty of Medicine, Khon Kaen University, Thailand \\ Correspondence should be addressed to Chalerm Eurboonyanun; chaleu@kku.ac.th
}

Received 22 September 2019; Accepted 27 November 2019; Published 6 December 2019

Academic Editor: Gabriel Sandblom

Copyright ( 2019 Chalerm Eurboonyanun et al. This is an open access article distributed under the Creative Commons Attribution License, which permits unrestricted use, distribution, and reproduction in any medium, provided the original work is properly cited.

Corrosive proctocolitis has occurred after accidental contamination of endoscopes in most patients. But accidental administration of corrosive agents for bowel cleansing can occur. The agents implicated for chemical colitis is $15 \%$ hydrochloric acid and $2 \%$ ethoxylated alcohol. We present a case of corrosive proctocolitis, present with anal pain and bloody diarrhea. Endoscopy revealed edema, erythema, and friability of the colonic mucosa. An experience of successful nonoperative treatments has been demonstrated.

\section{Introduction}

Corrosive proctocolitis has previously occurred by contamination of endoscopic cleansing liquid [1-3]. Some enema, such as soap and detergent, can also cause proctocolitis $[4,5]$. However, accidental administration of toilet cleaning agents rarely occurs. We describe one such unusual case of caustic colitis that was the encounter in this situation.

\section{Ethical Consideration}

This retrospective case report was approved by the Ethics Committee for Human Research based on the Declaration of Helsinki and the ICH good clinical practice guidelines. Clinical data were obtained by reviewing medical records.

\section{Case Presentation}

A Thai 80-year-old male was admitted to the hospital with a history of anal pain and bloody diarrhea without abdominal pain. His symptoms occurred five hours after accidental enema administration to relive constipation with liquid toilet cleaners (15\% hydrochloric and $2 \%$ ethoxylated alcohol, $\mathrm{pH}$ 0.5-1.0).

A physical examination revealed mild anal pain without abdominal pain nor guarding. Blood test showed a hemoglobin of $13.1 \mathrm{~g} / \mathrm{dL}$, white blood cell count of $17,900 / \mu \mathrm{L}$, and platelet count of $218,000 / \mu \mathrm{L}$.

Acute abdominal film (Figures 1(a) and 1(b)) shows a decreased amount of bowel gas in the lower abdomen/pelvic cavity.

The patient was diagnosed with corrosive proctocolitis. He was conservatively treated with intravenous antibiotics and fluid replacement therapy, restricting the oral intake of food/liquids for 2 days before elective colonoscopy. Colonoscopy showed circumferential friability, whitish membrane, edema, erythema, and superficial ulceration of mucosa from the anus to the sigmoid colon (Figures 2(a) and 2(b)).

After colonoscopy, the patient was able to consume a soft diet orally without abdominal discomfort. His bleeding and pain had also improved. He was discharged on the $5^{\text {th }}$ day after admission. 


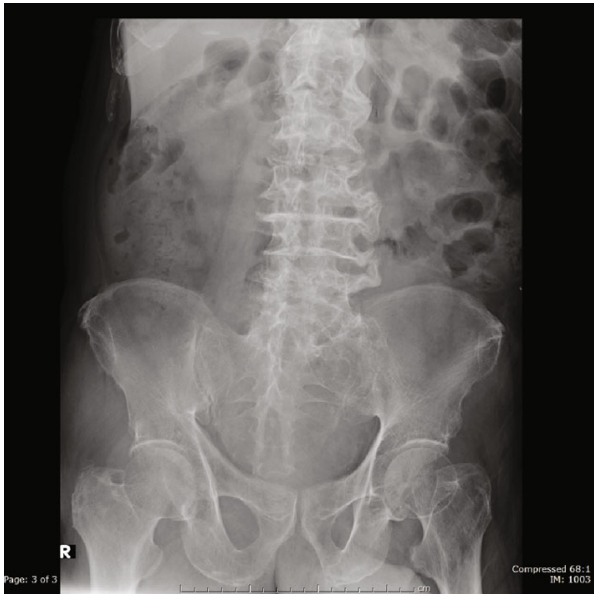

(a)

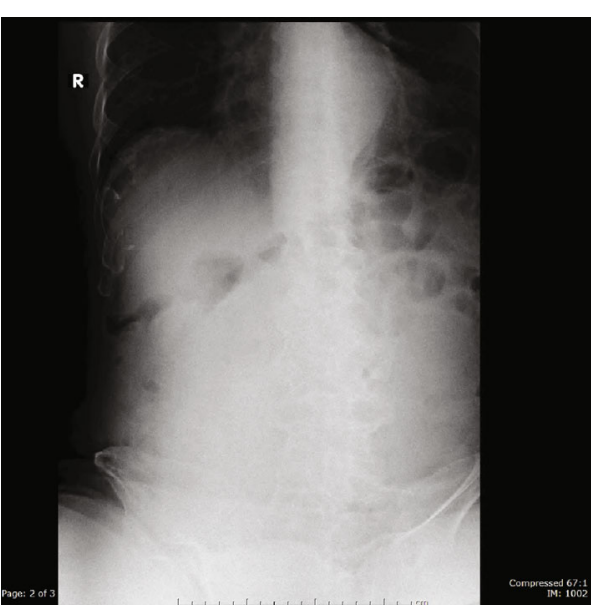

(b)

Figure 1: (a, b) Supine and upright abdominal radiographs show decreased amount of bowel gas in the lower abdomen/pelvic cavity.

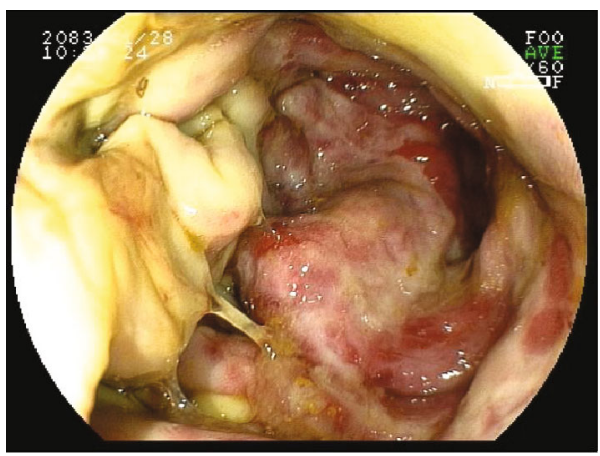

(a)

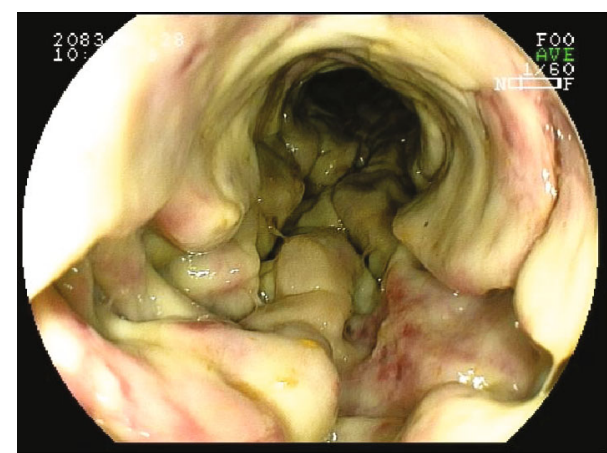

(b)

Figure 2: (a, b) Circumferential friability, whitish membrane, edema, erythema, and superficial ulceration of mucosa from the anus to the sigmoid colon.

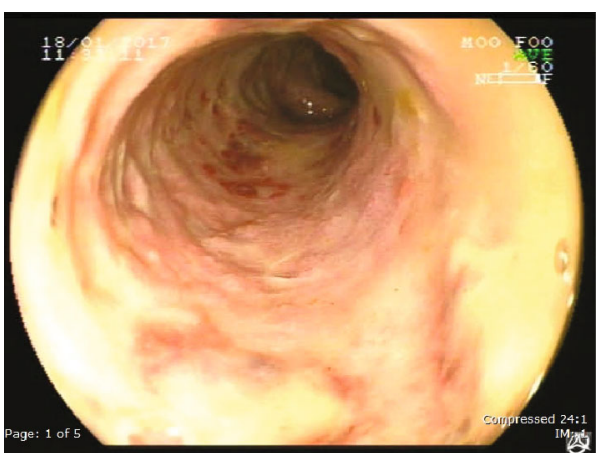

(a)

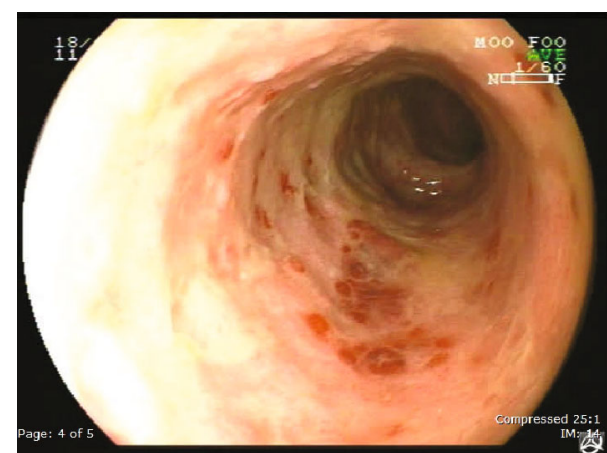

(b)

FIGURE 3: (a,b) Slightly pale mucosa with focal area of erythema from the anus to the sigmoid colon with narrowing of the caliber of the sigmoid colon.

Six weeks after, repeated colonoscopy showed whitish membrane, erythema, and stricture from the anus to the sigmoid colon (Figures 3(a) and 3(b)). One year after, he still had constipation, but he denied any further investigation or surgery. He had used saline enema to relieve constipation.

\section{Discussion}

Chemical proctocolitis is less common compared to chemical esophagitis for suicidal intent in adults. Chemical colitis has been reported to occur after the rectal administration of 
various chemicals including alcohol, detergent, hydrogen peroxide, glutaraldehyde, herbal medicine, and strong acids/base. One of the most common causes is residual glutaraldehyde on the surface of the endoscope after the cleaning procedure [6]. Hydrogen peroxide is also a common cause of chemical colitis, which some people believe to be a home remedy for constipation in children $[7,8]$. Most chemical proctocolitis patients were successfully treated with a conservative strategy with bowel rest and parenteral hydration. But there is no management guideline following endoscopic findings as corrosive esophagitis described by Zagar et al. to predict outcomes [9].

In this case, chemical proctocolitis is caused by very rare agents such as the toilet cleaner. An experience of successful nonoperative treatments in the modified Zagar classification grade IIB had been demonstrated. Although the colonic stricture occurred, there was no need for any other operation.

In conclusion, the patient who presented with corrosive proctocolitis was able to be treated conservatively in the acute phase. However, colonic stricture can occur in the late phase, but any other procedures to reduce late complications require further investigation.

\section{Disclosure}

This paper has been presented as a poster in the Scientific Session of the 16th World Congress of Endoscopic Surgery, Jointly Hosted by Society of American Gastrointestinal and Endoscopic Surgeons (SAGES) \& Canadian Association of General Surgeons (CAGS), Seattle, Washington, USA, 1114 April 2018: Poster Abstracts.

\section{Conflicts of Interest}

The authors declare that they have no conflicts of interest.

\section{References}

[1] S. Sheibani and L. B. Gerson, "Chemical colitis," Journal of Clinical Gastroenterology, vol. 42, no. 2, pp. 115-121, 2008.

[2] A. B. West, S. F. Kuan, M. Bennick, and S. Lagarde, "Glutaraldehyde colitis following endoscopy: clinical and pathological features and investigation of an outbreak," Gastroenterology, vol. 108, no. 4, pp. 1250-1255, 1995.

[3] R. E. Pumphrey, "Hydrogen peroxide proctitis," American Journal of Surgery, vol. 81, no. 1, pp. 60-62, 1951.

[4] B. F. Pike, P. J. Phillippi, and E. H. Lawson, "Soap colitis," The New England Journal of Medicine, vol. 285, no. 4, pp. 217-218, 1971.

[5] S. K. Kim, C. Cho, and E. M. Levinsohn, "Caustic colitis due to detergent enema," American Journal of Roentgenology, vol. 134, no. 2, pp. 397-398, 1980.

[6] H.-Y. Shih, D.-C. Wu, W.-T. Huang, Y.-Y. Chang, and F.-J. Yu, "Glutaraldehyde-induced colitis: case reports and literature review," The Kaohsiung Journal of Medical Sciences, vol. 27, no. 12, pp. 577-580, 2011.

[7] E. Schwartz, M. A. Dabezies, and B. Krevsky, "Hydrogen peroxide injury to the colon," Digestive Diseases and Sciences, vol. 40, no. 6, pp. 1290-1291, 1995.
[8] D. Pawar, A. Calara, R. Jacob, N. Beck, and A. N. Peiris, "Hydrogen peroxide induced colitis: a case report and literature review," Case Reports in Gastrointestinal Medicine, vol. 2017, Article ID 6432063, 6 pages, 2017.

[9] S. A. Zargar, R. Kochhar, S. Mehta, and S. K. Mehta, "The role of fiberoptic endoscopy in the management of corrosive ingestion and modified endoscopic classification of burns," Gastrointestinal Endoscopy, vol. 37, no. 2, pp. 165-169, 1991. 


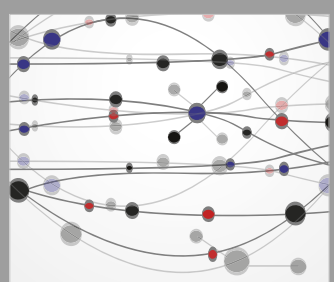

The Scientific World Journal
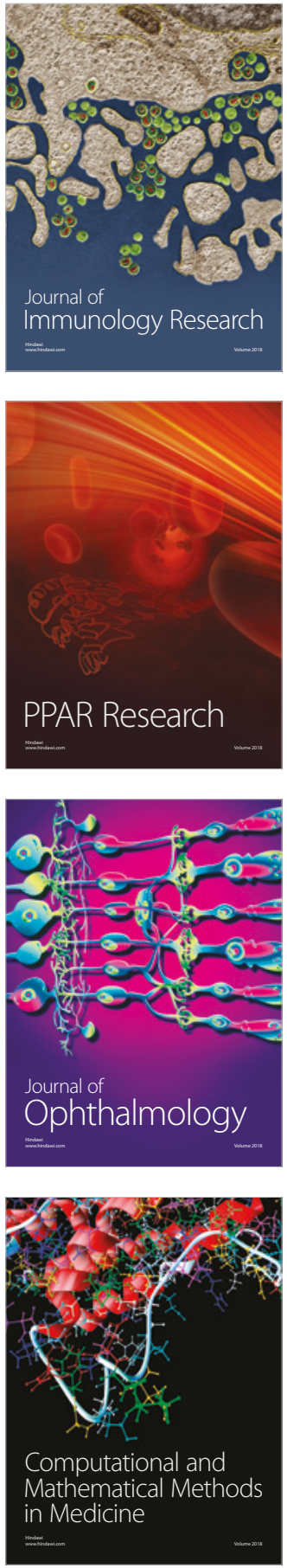

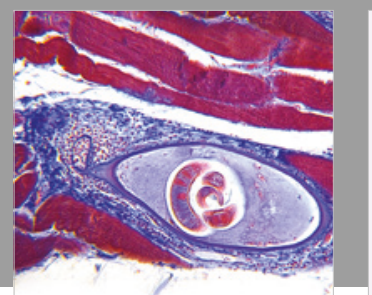

Gastroenterology Research and Practice

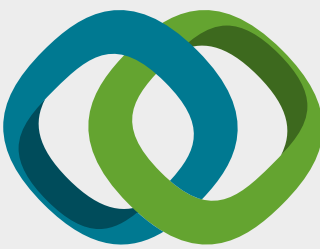

\section{Hindawi}

Submit your manuscripts at

www.hindawi.com
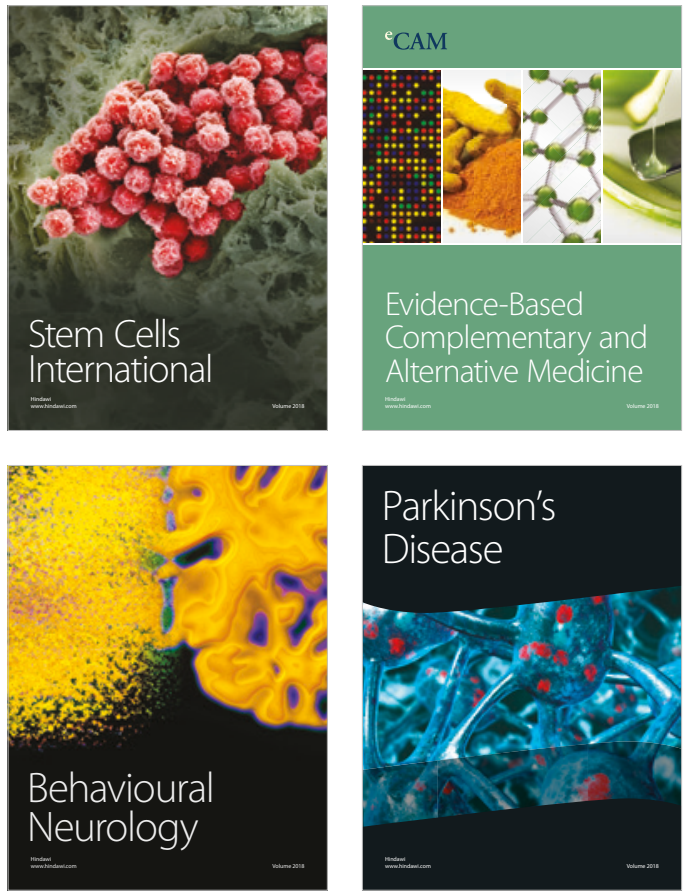

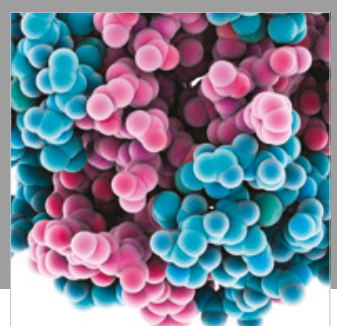

ournal of

Diabetes Research

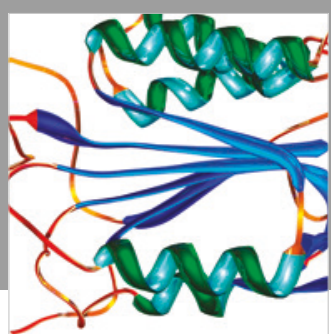

Disease Markers
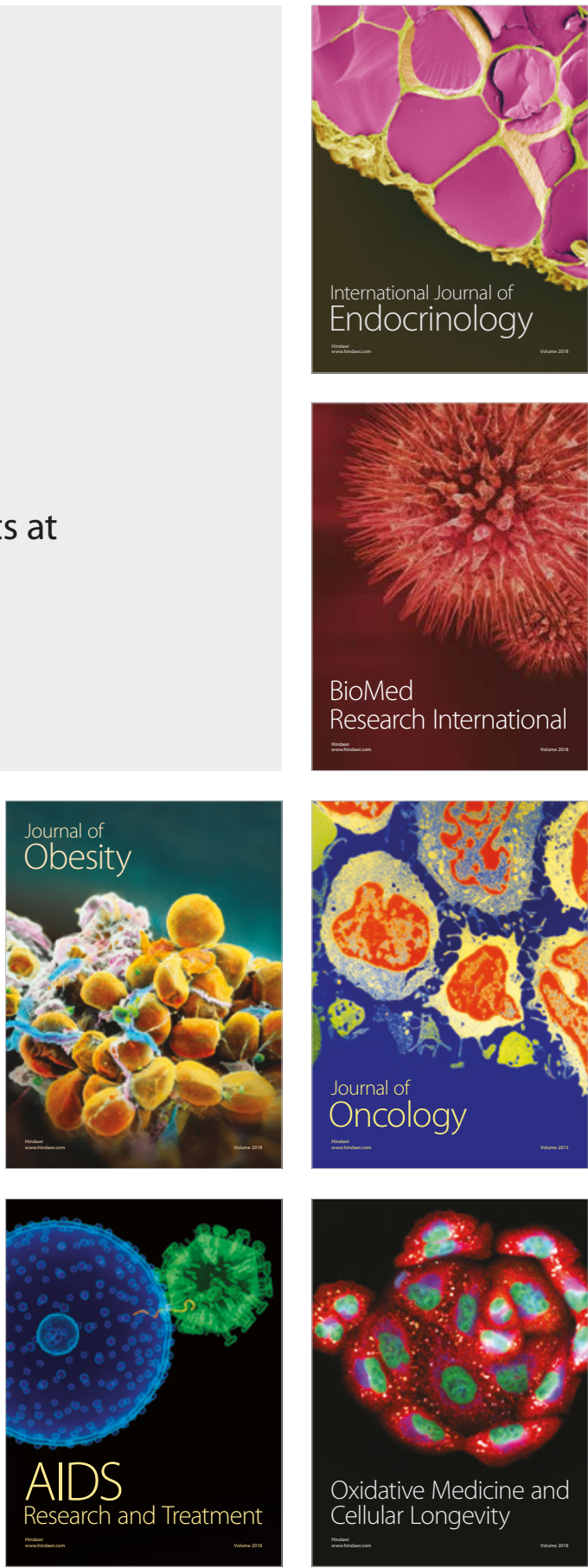